\title{
Afirmando-se a vida, constrói-se o tempo: experiência, emoções e ativismo político contra a AIDS $^{1}$
}

\author{
Carlos Guilherme Octaviano do Valle*
}

\section{Resumo}

Este artigo tem o objetivo de discutir a relação entre o ativismo biossocial e político de HIV/AIDS e a linguagem cultural das emoções. Minha proposta enfoca dois eixos específicos de análise: 1) a formação de sujeitos soropositivos, isto é, a sua automodelação como pessoas "vivendo com HIV" e, em razão disso, 2) a sua inserção e formação como ativista no movimento biossocial de HIV/AIDS. Por um lado, a testagem anti-HIV é um evento central de um longo processo de automodelação e construção identitária que evidencia a importância das emoções. Por outro lado, a participação de pessoas de diversos status sorológicos em atividades das 0NGs, grupos de ajuda mútua, redes ativistas, possibilita entender a micropolítica das emoções, dos corpos e das performances culturais que estão diretamente associadas à epidemia. Este artigo está baseado em pesquisa que vem sido conduzida pelo autor.

\section{Palavras-chave}

AIDS. Emoções. Ativismo.

\section{Abstract}

This article aims to discuss the relationship between biosocial and political activism regarding AIDS and the cultural language of emotions. My proposal is focused on two specific axes of analysis. Firstly, the formation of HIV-positive individuals, in other words, their self-shaping

\footnotetext{
* Carlos Guilherme Octaviano do Valle é professor associado IV, vinculado ao Departamento de Antropologia e Programa de Pós-Graduação em Antropologia Social, Universidade Federal do Rio Grande do Norte (UFRN). É graduado em Ciências Sociais (UFRJ) e Mestre em Antropologia Social (Museu Nacional/UFRJ). Fez seu doutorado na Universidade de Londres, defendendo a tese The Making of 'People Living with HIV and AIDS: identities, illness, and social organization in Rio de Janeiro, Brazil (2000). Possui interesse de pesquisa em antropologia da saúde e doença, AIDS, biossocialidades, doenças raras, antropologia das emoções, ativismo e movimentos sociais, sexualidades e corpo. Email: cgvalle@gmail.com.

${ }^{1}$ Este texto é uma versão do trabalho apresentado no Seminário Temático 5 - “Corpo, saúde e emoção", 34 Encontro Anual da ANPOCS (Caxambu, 2010), coordenado por Maria Claudia Coelho (UERJ) e Cynthia Sarti (UNIFESP). Gostaria de agradecer à debatedora e aos participantes do GT por seus comentários, que contribuíram para a reformulação do texto. Agradeço também as sugestões a uma nova versão feitas pelas organizadoras. Este artigo faz parte da produção do projeto de pesquisa "Memória, Moralidade e Política: reconsiderando o ativismo HIV/ Aids na década de 2010".
} 
as people "living with HIV" and, because of that, secondly, their insertion and formation as activists in the HIV/AIDS biosocial movement. On one hand, the anti-HIV test is a central event of a long process of self-shaping and identity building, which substantiates the importance of emotions. On the other hand, the participation of people in various HIV-positive status in NGO activities, mutual help groups and activist networks make it possible to understand the micropolitics of emotions, bodies and cultural performances that are directly associated with the epidemics. This article is based on the research the author has been leading.

\section{Keywords}

AIDS. Emotions. Activism.

\section{Introdução}

No presente artigo, discuto a relação entre emoções e o problema da infecção do HIV a partir de dois focos distintos, mas que se intersectam: a automodelação de uma pessoa com HIV, isto é, soropositiva², e o modo como ela se forma como ativista em termos de suas práticas e significados político-ideológicos. Darei ênfase, por um lado, aos aspectos e efeitos que envolvem a testagem anti-HIV, e, por outro lado, ao processo de inserção em organizações, grupos e redes ativistas, qual seja, o chamado movimento social de HIV/Aids. Nos dois focos, reflito sobre a dimensão crucial das emoções para se entender a formação de sujeitos e da existência do ativismo político.

Entendo as emoções como sendo definidas e vividas em termos culturais e sociais. O papel da cultura na experiência das emoções é visto normalmente como secundário e "mesmo que as emoções possam ser frequentemente vistas como evocadas através da vida social, são raramente apresentadas como um índice de relações sociais, tematizadas mais como um signo de estado pessoal ou individual" (LUTZ, 1988 - tradução minha). Devese salientar que há estreita relação entre a construção das emoções e seus modos de enunciação discursiva (ABU-LUGHOD; LUTZ, 1990; COELHO, 2010; COELHO; REZENDE, 2010). Entendo que a linguagem e as práticas

\footnotetext{
${ }^{2}$ Soropositivo e soronegativo eram as categorias identitárias mais empregadas no mundo social que pesquisei. HIV positivo e HIV negativo eram termos também usados.
} 
discursivas têm importância crucial para este artigo, pois expõem como as emoções estão associadas a contextos e experiências sociais particulares que descortinam as socialidades e as relações de poder em jogo. Assim, privilegiando as práticas discursivas, as conversações, os modos de enunciação e as textualidades, considero sua dimensão cultural, política e poética simultaneamente em termos de sua força pragmática, expressada através de um foco direto nas emoções como práticas discursivas (ABULUGHOD e LUTZ, ibid, p.10), que comunicam explícita e publicamente sobre a vida social, justificando sua evidente eficácia societária através de performances emocionais.

Além disso, precisamos destacar a relação entre emoção, corpo e discursividade. Pode-se entender as emoções como uma prática ideológica, que envolve uma economia e um trabalho específico, entendido, segundo Lutz, como um 'trabalho emocional' (1988) que se apresenta através da complexidade das linguagens, sejam elas orais/verbais como corporificadas através de gestos, posturas, expressões físicas, etc. Se o corpo precisa ser encarnado em termos de suas significações culturais, não somente em termos de sua objetividade física, sua própria materialidade exprime a significação pela qual as emoções podem ser experimentadas. Nesse sentido, a experiência é emocional e, também, relacionada a significações definidas em termos sociais e culturais particulares. Devo destacar que as emoções são definidas conceitualmente - amor, raiva, medo, nojo, tristeza - implicando ideias ou:

\footnotetext{
“elementos de prática ideológica local, que envolvem negociação sobre o significado dos eventos, sobre direitos e moralidades, sobre o controle de recursos - em resumo, envolvem lutas sobre o mais amplo conjunto de questões concernentes aos grupos humanos e sociais". (LUTZ, 1988, p.5).
}

Elas podem ser entendidas, compartilhadas, contestadas e silenciadas, emergindo através das próprias interações entre pessoas e as coletividades que representam. Desse modo, darei mais ênfase às interações, às práticas discursivas e aos significados emocionais produzidos em contextos historicamente específicos, o que supõe considerar as dinâmicas societárias e as relações de poder na vida cotidiana.

Cientistas sociais têm mostrado que os estudos sobre os movimentos sociais em sua relação com as emoções se fortaleceram a partir da década de 1990, destacando que a ação política é permeada pela dimensão das emoções 
(GOODWIN et al., 2001; FLAM; KING, 2005; GOODWIN; JASPER, 2006). Não se aceita, assim, o dualismo entre uma proposta política vista como "racional" e o plano da expressão emocional, entendida como "irracional". Em minha pesquisa, abordei inicialmente a mobilização societária e política a partir da epidemia do HIV/ Aids (VALLE, 2000; 2002; 2008), que constituiu um mundo social específico, composto por entidades civis, as ONGs Aids, grupos de ajuda mútua e redes de pessoas com HIV, que interagiam com esferas clínicas e de tratamento, agências governamentais e globais, muitas delas de financiamento internacional. Esse mundo social heterogêneo compôs a etnografia que conduzi na década de 1990 e sofreu mudanças significativas até os dias correntes (VALLE, 2013). Ao considerarmos a história social e cultural da epidemia do HIV/Aids, pode-se enfocar sua dimensão política, relevando-se as diversas articulações entre políticas públicas, estruturas de saúde, o alcance das intervenções biomédicas, além dos efeitos das mais variadas formas de organização civil (PARKER, 1994; GALVÃO, 2000; SILVA, 1999).

Assim, refleti a respeito das relações existentes entre os efeitos da mobilização sociopolítica e as dinâmicas identitárias, desenroladas muitas vezes de modo extremamente tenso e emocional. Modelos ideológicos distintos de construção identitária foram operantes, alguns reforçando particularismos da experiência 'soropositiva' e outros, ao contrário, estimulando o compromisso solidário do 'viver com Aids', independente do status sorológico da pessoa. Esses dilemas político-identitários estiveram presentes na trajetória de boa parte das ONGs Aids brasileiras, especialmente as do Rio de Janeiro. A ideologia do Grupo Pela Vidda (GPV, daqui em diante) $)^{3}$, que salientava o valor universalista da 'solidariedade', opunha-se a outras formas de organização e significação, mais particularista, do 'viver com Aids', tal como privilegia a Rede Nacional das Pessoas Vivendo com Aids $(\mathrm{RNP}+)$. Esse antagonismo político entre modelos ideológicos e societários, cujos princípios resguardavam questões identitárias, tiveram paralelos em uma esfera global, embora apresentando-se de modo singular em outros contextos societários (ARISS; 1997; GOULD, 2009; NGUYEN, 2010).

\footnotetext{
${ }^{3}$ O Grupo Pela Vidda (Rio) foi criado em 1989 por iniciativa do escritor Herbert Daniel, que atuava, então, na Associação Brasileira Interdisciplinar de AIDS (ABIA). Junto do GIV (Grupo de Incentivo à Vida), fundado em São Paulo, o GPV foi uma das primeiras ONGs a estimular a participação de "pessoas vivendo com HIV e AIDS".
} 
Independente dos conflitos entre organizações, entidades e modelos ideológicos de construção e representação do 'viver com Aids' e das identidades em jogo, as emoções, entendidas como elaboradas e reconstituídas social e culturalmente em práticas cotidianas, foram sempre canalizadas e mobilizadas como uma linguagem para dar sentido aos modos de se engajar e atuar, em termos socialmente plurais, diante dos efeitos da epidemia e do cotidiano de mal-estar, das enfermidades e das variadas desestruturações da vida social. Por um lado, as emoções seriam foco de preocupação na medida em que se pensava que a doença desestabilizava e reordenava de modo não esperado trajetórias e projetos de vida, previamente delineados e/ou estruturados, o que vem colocar uma questão própria da temática antropológica da experiência das doenças. As ONGs Aids e as estruturas de saúde montaram estratégias, cada uma partindo de seus próprios modelos de ação e das suas condições de possibilidade, para lidar com o caráter 'subjetivo' da doença e do sofrimento social que a Aids pode acarretar. Essas estratégias podiam estimular atividades de caráter terapêutico-reflexivo, muitas vezes coordenadas por especialistas como psicólogos, psicanalistas e assistentes sociais, que disseminavam sua própria interpretação dos efeitos psicológicos da Aids. Essas práticas, que estou chamando de terapêutico-reflexivas, que se aproximam da ideia de tecnologia confessional proposta por Vinh-Kim Nguyen (2010), investiam na construção de sujeitos mobilizados através de ações e ideias que mobilizavam emoções em prol de uma vida mais "saudável", apesar da doença, contrariamente aos significados de fatalidade e morte cristalizados pela identidade estigmatizada do "aidético", criada no contexto brasileiro na década de 1980 (VALLE, 2002; SEFFNER, 1995).

Por outro lado, as emoções seriam alvo de canalização e reorientação em termos da sua apropriação política, quando a conscientização e o engajamento das pessoas HIV positivas eram considerados em vista da sua autoconstrução como modelos e figuras exponenciais de ativismo social. Às vezes, tornavam-se "figuras emblemáticas da Aids" (SILVA, 1999), que nem Herbert de Souza e Herbert Daniel, duas lideranças importantes do ativismo de $\mathrm{HIV} /$ Aids, cujas trajetórias estiveram associadas à criação de ONGs, como a ABIA e o GPV. Certamente, as ideologias ativistas se constituem a partir da força e mobilização de emoções expressadas e exibidas por pessoas, lideranças e agentes específicos (GOODWIN et al., 2001, p.18). Em minha pesquisa, vergonha, medo, tristeza, raiva foram algumas das emoções mais aludidas a fim de falar da Aids, da infecção do 
HIV, da experiência singular da soropositividade, etc. Mas as atividades de caráter público, tais como protestos e manifestações, participação em eventos, divulgação do ativismo por meio dos meios de comunicação de massa ou de projetos mais específicos (teatro, performances) poderiam produzir, em termos mais gerais, um compromisso diante da epidemia, além de criar forte ressonância cultural e emocional que ajudasse a entender a epidemia e, ainda mais, constituísse a dinâmica própria do movimento social (EPSTEIN, 1996).

Nessas duas formas de foco, que não podem ser separados e envolvem tanto experiências particulares como práticas ativistas públicas, as emoções podem ser vividas, performatizadas e ritualizadas diferentemente. Contudo, os dois focos possuem elementos convergentes no que diz respeito a seus objetivos, significados e intenções. Evitando-se qualquer dualismo que perfaça uma diferença substancialista, os focos apontados devem ser pensados como construções analíticas, ou seja, tal como diria Elias (1994, p.11), ideias e emoções são "duas camadas inseparáveis, interdependentes" que constituem as vidas das pessoas em termos de suas ações. Em suma, as emoções precisam ser consideradas de modo complexo, enfatizando as práticas sociais e os agenciamentos pessoais como sendo inevitáveis para seu entendimento, quando a família, as redes de relações e as inserções em grupos e instituições variadas são perpassadas por uma dimensão afetiva. Isso acontece no caso do mundo social da Aids e dos grupos, ONGs e redes que eu pesquisei. De fato, as relações familiares, as parcerias sexuais e as amizades também estavam incorporadas nas dinâmicas que constituíam esse mundo social, pois pais, mães, irmãs, namorados e esposas têm sido presença frequente do cotidiano das ONGs e nos contextos médicos. Devese considerar, então, uma micropolítica das emoções (COELHO, 2010; COELHO; REZENDE, 2010), o que exige uma etnografia das dinâmicas societárias e das relações de poder entre pessoas e grupos, mobilizados através de um trabalho emocional.

\section{Doença, Estigma e Emoções: contra o medo, buscando ajuda e tornando-se ativista}

No início da década de 1980, a epidemia da Aids tornou-se grave problema global de saúde. Logo o Brasil se tornou um dos quatro países com maior incidência de casos de Aids no mundo, o mais alto na América 
Latina. Até junho de 2016 (MINISTÉRIO DA SAÚDE, 2016), o número acumulado de casos de Aids chegou a 842.710: 548.850 homens (65,1\%) e 293.685 mulheres (34,9\%). Embora associada à homossexualidade, a epidemia afetou heterossexuais desde o início. Assim, as mulheres têm sido infectadas, sobretudo, por transmissão heterossexual (GUIMARÃES, 2001; MINISTÉRIO DA SAÚDE, 2016). Uma das mais notáveis características do perfil brasileiro da epidemia é a heterogeneidade social na transmissão do HIV (PARKER, 1990).

Desde sua eclosão, pode-se afirmar que o senso comum da Aids envolve valores negativos de conotação moral, salientando significados de morte e doença. Talvez o senso comum fosse mais notavelmente circulado através da imprensa, disseminando-se como modo de compreensão cultural da epidemia. A partir da década de 1980, os meios de comunicação de massa passaram a produzir, circular e cristalizar imagens, discursos e significados de medo, perigo e violência sobre a epidemia da Aids, o que nos permite pensá-la como um fenômeno cultural que vem sendo reconfigurada historicamente nas últimas três décadas (VALLE, 2000; 2002). O caráter inevitável da morte por Aids foi um dos temas mais repetidos na imprensa, caracterizando um senso comum, difuso e ambíguo, obviamente estigmatizante sobre a síndrome. A Aids era considerada uma "doença 100\% fatal", "traiçoeira", uma "batalha inútil contra a morte". Assim, metáforas de crime e condenação moral eram associadas à Aids. Muitas vezes, o "portador de Aids" era considerado uma pessoa "condenada à morte". Foi o cantor do pop-rock brasileiro, Cazuza, aquele que mais corporificou publicamente a concepção cultural da doença de decadência física e da fatalidade que a Aids produzia. De 1989 a 1990, quando faleceu, a imprensa cobriu regularmente sobre ele em tom dramático e, muitas vezes, negativo. A reportagem de capa da Veja chegou a afirmar: "Cazuza, uma vítima da Aids agoniza em praça pública" (VEJA, 1989). A "cara de Cazuza" como a "face da AIDS" tornou-se a mais conhecida imagem cultural corporificada de um "aidético".

Segundo Sontag (1983), nenhuma doença deve ser compreendida através de metáforas que descrevam a realidade de modo obscuro. Mas como escapar do sentido emocional que se adquire através da compreensão de tais metáforas culturais? A Aids foi constituída como um fenômeno cultural de forte conotação moral, expressando significados negativos sobre sexualidade e estilos de vida específicos, visto sua longa associação com a ideia de promiscuidade. Esses significados eram associados de modo 
acusatório e direto, sobretudo, às homossexualidades, a certas pessoas e grupos, o que explica como sua dimensão moral podia remeter-se às emoções que envolviam nojo, raiva, desprezo ou medo, vergonha e culpa, respectivamente, para seus acusadores e seus acusados. Os discursos, as textualidades (tal como da imprensa) e as práticas narrativas que abordam a Aids produziam significados de medo e agressividade identificados a certas pessoas e grupos moralmente condenáveis, explicitando as dimensões de violência simbólica e das relações de poder em termos de uma linguagem e retórica emocional, condizente de um verdadeiro "pânico moral" (COHEN, 1972). Todos esses discursos da Aids eram citados entre meus interlocutores como elementos centrais de compreensão cultural do estigma e do medo, vergonha e culpa associados aos riscos de infecção do HIV e da doença.

Em minha pesquisa, foi possível notar o quanto a descoberta da infecção do HIV, a evidência biomédica do status sorológico e a confrontação da soropositividade, a ser construída e experimentada em vida, seriam tomadas como eventos relevantes, dramáticos, para meus interlocutores de pesquisa. Em nossas conversas e entrevistas, percebi como tais eventos e situações associavam-se a certas emoções, tais como medo, tristeza e sofrimento. Quase narrativas, as falas recuperavam fatos e contextos que desnudavam um suposto risco de infecção pelo HIV, o medo rondando a testagem e a descoberta do status sorológico e, sobretudo, o impacto que causava na vida e nas trajetórias pessoais, considerando as relações com a família, com os parceiros sexuais, com amigos, etc. Nas conversas, apresentava-se uma interação complexa entre a aquisição gradativa de conhecimento técnicocodificado, sobretudo biomédico, e a construção cultural das emoções, o que poderia elucidar o modo como a Aids tem sido construída e interpretada, quando as emoções poderiam ser apresentadas, contestadas ou controladas através de estratégias discursivas socialmente compartilhadas.

Em 1985, a testagem laboratorial foi introduzida para diagnosticar a presença de anticorpos do HIV e, depois disso, essa tecnologia biomédica tornou-se amplamente aceita pelas políticas públicas de saúde. Na década de 1980, era muito comum, porém, a desconfiança sobre a precisão do teste anti-HIV. Mesmo a imprensa chegou a divulgar que um resultado "falso positivo" podia levar "centenas de pessoas a passarem por momentos de desespero". Assim, a testagem anti-HIV tratava-se de um evento que foi construído culturalmente como crucial, um marco nas vidas das pessoais atingidas pela epidemia. Cheguei a constatar sua importância para meus interlocutores de pesquisa. Quando perguntava como souberam de seu status 
sorológico, muitas pessoas respondiam por meio de relatos e narrativas que descreviam o período anterior e posterior ao exame. Mesmo em contextos informais, muitos HIV positivos falavam da incerteza que rondou o período de testagem. Confirmei a mesma apreensão entre pacientes soropositivos de hospitais sem qualquer afiliação a uma ONG.

Quando a testagem era abordada nas conversas, aparecia uma nítida diferença, embora articulada através de uma linha de continuidade temporal, entre a decisão e a ação concreta de fazer o exame anti-HIV e a obtenção, também concreta, do resultado. No Brasil, o período entre a testagem anti-HIV e a entrega do resultado costumava ser longo, sobretudo até meados da década de 1990, especialmente se a testagem era realizada em um serviço público de saúde. Normalmente, levava mais de um mês para uma pessoa receber o resultado do exame. Esse tempo de espera era longo e entendido como um evento de enorme intensidade emocional. Em muitos casos, esbarrando em práticas de segredo e recobrimento social. Essa etapa de incerteza "sorológica" podia ser prolongada, indicando uma situação de liminaridade, quando o resultado era considerado indeterminado e, portanto, o exame tinha de ser refeito, um problema comum na primeira década da testagem anti-HIV. Os resultados "indeterminados" e o temor quanto aos resultados "falso-positivos" ou "falso-negativos" aumentavam a suspeita sobre a confiabilidade dos exames anti-HIV como uma tecnologia biomédica criteriosa. A indefinição sorológica podia ser, assim, estendida ao longo do tempo. Vários interlocutores reportaram longos períodos de indeterminação sorológica, quando os exames eram repetidos diversas vezes até a comprovação da soropositividade. Alguns deles buscaram confirmar os resultados pela segunda até mesmo uma terceira vez, o que sugere o valor estratégico do sentido de "esperança". Essa estratégia era mais comum entre as pessoas que não estavam doentes, nem tinham passado por uma mudança substancial em sua rotina de vida. Evidenciavase uma espécie de "tecnoneurose" (BIEHL et al., 2001), quando o aparato de uma tecnologia biomédica específica, a testagem anti-HIV, produzia uma verdade (se o teste era positivo ou negativo etc.), que mobilizava emocionalmente a pessoa que desejava conhecer seu status sorológico.

Como um evento crítico (DAS, 1996), a testagem anti-HIV suscitava a ruptura de expectativas e de trajetórias, quando o próprio mundo que define a experiência da vida considerada saudável era desfeito. As expectativas de vida seriam ameaçadas e se fragmentavam quando as "explicações convencionais parecem inadequadas" (STRAUSS, 1999: 55). A experiência 
da doença coloca em aberto um conjunto de certezas e expectativas. Como esses dilemas são descritos por meio de uma reconstrução narrativa do tempo, o evento dramático pode ser definido como momento de extrema densidade emocional, quando se acredita que as emoções dominam. Praticamente, nenhum interlocutor de pesquisa descreveu o contexto pósteste como sendo tranquilo, com exceção daqueles que se descobriram soronegativos. Diversos interlocutores usaram metáforas espaciais, tanto de queda como profundidade, que caracterizavam o período da descoberta da soropositividade: "Tudo desmoronou completamente"; "Eu entrei num maior buraco, entende?". Ou ainda as ideias envolvendo peso e volume: "[O resultado soropositivo] foi muito pesado no início".

Meus interlocutores mostravam que as concepções culturais da morte apareciam de imediato após o recebimento do exame. A Aids era associada com uma morte rápida e terrível, reinterpretando as imagens culturais da imprensa brasileira. A decisão de escrever um testamento podia ser tomada ou, ao contrário, um resultado HIV-positivo levava a pessoa a um período de dilapidação dos recursos econômicos e de abertura ao excesso, "enquanto ainda havia tempo". Significados de urgência pareciam prevalecer numa luz diferente do que se suspeitava antes. Os significados do 'futuro' tornavam-se problemáticos. De modo geral, essa incerteza era descrita por meus interlocutores como um contexto de crise. De acordo com vários relatos, um conjunto elevado de emoções descontroladas caracterizava a vida de cada pessoa. A experiência da Aids emergia como uma ruptura na vida emocional, que precisava, então, ser propriamente controlada ou reconstruída por uma forma ulterior de controle reflexivo e racionalizado.

Não podemos generalizar, pois as falas, os relatos e narrativas apresentaram diferenças em termos de gênero. Havia uma preocupação acentuada entre as mulheres heterossexuais do perigo de infecção de outros familiares. Homens heterossexuais e homossexuais mostraram mais preocupação quanto ao risco de infecção dos seus parceiros sexuais e de seu verdadeiro status sorológico. Contudo, era um pouco menos pronunciado do que entre as mulheres de evitarem a infecção de seus filhos e netos, o que levanta a questão dos valores e significados de cuidado associados à feminilidade. Essas especificidades eram apresentadas no bojo de um esquema narrativo estruturado que parecia ser bastante difuso. Quando eram relatados os riscos e a infecção do HIV podia estar presente, sobretudo, a culpabilização de certas pessoas, o que acentuava a raiva de quem era suspeito pela infecção. Emoções variadas podiam oscilar e mesclar entre 
si, articulando significados tanto de pena, tristeza, raiva como amor, especialmente entre pessoas que se sentiam vitimadas pela infecção. Antigos parceiros, sobretudo homens, podiam ser vistos como responsáveis pela infecção do HIV. Aqui, a dimensão social e cultural da lealdade e do amor eram muito notados, expondo as hierarquias de gênero e relações de poder, anunciadas pela conjugalidade, sobretudo heterossexual (KNAUTH, 1998; GUIMARÃES, 2001).

$\mathrm{Na}$ maioria das entrevistas em que apareciam relatos sobre testagem anti-HIV e a descoberta do status sorológico, o período pós-exame e de entrega do resultado seria considerado uma trajetória complexa cheia de oscilações. Havia a descrição de um período marcado por transição e por contingência crítica, que, na reconstrução autobiográfica, era vivido intensamente, segundo os termos mais usados, como um "golpe, uma "pancada", um "choque" pessoal, mobilizado por extrema tristeza. Todos esses estados expressavam o domínio de emoções fora de controle. Perturbador, esse estágio era parte de uma estrutura temporal que definia a trama por meio da qual as histórias biográficas da Aids seriam construídas. Elas podiam ser histórias de pessoas HIV positivas, mas podiam também estruturar histórias soronegativas e daqueles que não eram testados, mas interagiam intimamente com uma pessoa soropositiva, o que acontecia com frequência nas ONGs. Sob o signo da transição, meus informantes reportaram ter vivido um longo, lento e extremamente frágil período no qual a prática do teste anti-HIV era apenas uma parte de sua história, um amplo processo de viver com o $\mathrm{HIV} /$ Aids, um processo diferenciado por onde se elaborava uma experiência, que deve ser entendida, portanto, a ser construída social e culturalmente. $\mathrm{O}$ peso do tormento emocional, que podia consistir de formas particulares de medo, insegurança e tristeza, era enfatizado pelo significado cultural da Aids como um mal ameaçador, letal, misterioso e incurável.

Deve-se ressaltar que meus interlocutores associavam esse contexto de emoções descontroladas à falta de um correto conhecimento sobre Aids. Esse período transitório, pesado e negativo era também um estágio de 'ignorância', quando as pessoas reconheciam suas falhas e equívocos prévios na "prevenção", isto é, na "informação" sobre o HIV. A fim de redimir esses equívocos anteriores e as falsas percepções que elas tinham, uma série de decisões pessoais e eventos, assinalados como cruciais, tornavam-se significativos para explicar outro movimento na reconstrução narrativa das práticas de vida, que envolviam tecnologias biomédicas, 
tal como a testagem anti-HIV e da inserção progressiva em um regime disciplinado de tratamento médico, usando remédios antirretrovirais, fazendo exames de carga viral e de CD4, etc. (VALLE, 2010; ARISS, 1997). Era esse reconhecimento dos erros e dos equívocos passados o que iria motivar que as pessoas buscassem "ajuda" e adquirissem "informação", tal como ouvi tantas vezes, ou seja, conhecer mais sobre a Aids e, por seu turno, provocar um exercício maior de reflexividade sobre a vida.

As questões que envolviam a experiência da doença podiam ser o vetor incisivo para a explicação da escolha de participação em uma ONG como o GPV, evocados em práticas comunicativas, a fim de registrar uma oposição aos significados de morte, doença e isolamento, salientados no senso comum da Aids e nas imagens estigmatizantes do aidético. A entrada na ONG implicava um sentido progressivo de autocontrole em termos da dimensão social, que se articulava à emocional, cuja intensidade girava, em grande parte dos casos, em torno das práticas terapêutico-reflexivas ou suscitadas através de práticas e tecnologias biomédicas. Elas servirão aqui para se entender a consolidação de estratégias de cuidado de si e de gestão das emoções, no contexto das ONGs Aids, onde se constituíram espaços e práticas mais específicas voltadas a um foco apropriado da subjetividade das pessoas soropositivas, qual seja, instâncias, contextos e ações, balizados por valores culturais sobre vida saudável e bem-estar, por onde as emoções poderiam ser expressadas e, ainda, canalizadas para o autocontrole pessoal, que reestruturasse momentos e situações passadas que eram compreendidos como emocionalmente perturbadores e desestruturados.

No caso do GPV, houve um estímulo, desde a criação da entidade em 1989, de que as pessoas pudessem se posicionar por meio de práticas discursivas que tivessem sentido terapêutico-reflexivo de autoexposição pessoal, consistindo verdadeiras tecnologias confessionais (NGUYEN, 2010). O próprio perfil social de classe média da maioria dos primeiros voluntários e diretores da ONG estimulava isso, que as pessoas pudessem expor suas ideias e formular conceitos que fossem discutidos coletivamente, embora articulados pela presença e direção carismática de seu principal fundador: Herbert Daniel. Essa discursividade reflexiva seria priorizada como uma meta a ser estimulada e alcançada em atividades de grupo.

A Tribuna Livre era a atividade mais concorrida, reunindo uma roda entre 30 a 50 pessoas, discutindo tema escolhido livremente. Essa atividade contribuiu para a modelação dos membros do GPV, enquanto ativistas e soropositivos, e, ao mesmo tempo, os formava através da discussão de 
temas que priorizassem saber técnico autorizado e qualificado. Nesse sentido, havia a convergência de uma reflexão crítica sobre a Aids, a discussão sobre as formas de preconceito e discriminação, a questão central do estigma da doença, além de preocupações mais incisivas sobre corpo, saúde e soropositividade. É crucial alertar que o incentivo das práticas discursivas entre os voluntários do GPV esbarrava com as diferenças sociais que caracterizavam a ONG (classe, gênero, sexualidade, etc.), imprimindo a seleção de quem falava ou de quem se silenciava ${ }^{4}$.

O exame anti-HIV, as incertezas de fazê-lo ou não, de revelar ou não o status sorológico seriam matéria de discussão de diversas atividades de caráter discursivo-reflexivo, como a Tribuna. Mas elas também eram abordadas especialmente nas reuniões de recepção e aconselhamento, que eram consideradas a 'porta de entrada' do GPV. Pouco tempo depois da criação da ONG, a atividade se tornou relevante, pois eram abordados ali temas sensíveis e inquietantes, especialmente a descoberta do status sorológico positivo do HIV. Assim, jovens psicólogos em fase de formação profissional passaram a ser escolhidos para coordenar a atividade, o que contribuiu para ajustá-la a um perfil reflexivo-terapêutico, apesar da insistência de que a atividade não era um serviço de apoio psicológico. A recepção era entendida como um espaço de entendimento básico dos princípios ideológicos do GPV, além de ser pensada como um lócus de transição entre dois mundos sociais, o exterior, da vida social e das ideias negativas sobre a Aids, encontradas no senso comum, e o mundo particular, privado da ONG. Esse lócus seria a passagem inicial e transitória de, digamos, 'descompressão' emocional, quando os valores morais mais negativos poderiam ser colocados em suspensão e criticados na forma devida. Desse modo, o coordenador da recepção buscava corrigir o neófito quando ele empregava a categoria aidético como termo de auto-atribuição, informando que o modo correto de identificação era soropositivo. Tratava-se de um espaço de transição e de incorporação preliminar de informação correta, cujo sentido era o de reorientar as emoções da pessoa de uma suposta situação de descontrole para um nível de autocontrole, tanto estimulado pela presença da pessoa na recepção, ao ser orientada pelo coordenador da atividade, como depois pela

\footnotetext{
${ }^{4}$ A Tribuna Livre mostrou pujança por mais de dez anos, perdendo intensidade com as transformações históricas da ONG desde o início do século XXI.
} 
integração do visitante ao GPV 5 .

Nas conversas, salientava-se de modo retrospectivo que as questões que envolviam o status sorológico e a experiência da soropositividade, sobretudo suas inquietações e temores, pudessem ser, aos poucos, redimensionadas por uma valorização da vida, o que explicaria a decisão de participação em uma ONG Aids. Esse aspecto é importante para pensar a inserção de uma pessoa em busca de ajuda e informação em uma ONG, tal como o GPV, primeiro como voluntário, mas essa participação, ao ser progressiva, levava a um processo de automodelação como ativista. Esse conjunto de expectativas e de valores de formação de uma pessoa comprometida, responsável e consciente sobre a prevenção da AIDS era um objetivo ideológico da ONG, que se articulava com a suposição de que o ativista tivesse alcançado um nível de consciência e, igualmente, de controle emocional. Deve-se ter cautela, porém, em dizer que o ativista se formava como um ator político "racional", calculista e sem emoções (GOODWIN; JASPER, 2006). Não se trata disso e deve-se ter cuidado ao fazer o contraste entre desordem/ ordem, descontrole/controle de emoções, porque se trata mais de uma reorganização do trabalho emocional pelo qual passa cada pessoa a partir de um evento crítico, como a descoberta do status sorológico para o HIV. Era necessário lidar com a "ambivalência" emocional constitutiva da experiência e da construção de identidades HIV+, cujos sentidos e investimentos se davam em oposição ao estigma da Aids, que gerava medo, vergonha e culpa, o que mostra associação direta com os discursos e emoções diante das homossexualidades, definidas historicamente em termos de uma ambivalência complementar de emoções: vergonha versus orgulho (GOULD, 2001; 2009) ${ }^{6}$.

Muita cautela deve-se ter ao se referir a um processo de automodelação ativista como se ele fosse homogêneo e uniforme. Muitas pessoas eram

\footnotetext{
${ }^{5}$ Percebe-se aqui um tema sociológico clássico, que se encontra na obra de Max Weber e Norbert Elias, que sugerem a importância do autocontrole e da responsabilidade pessoal para entender a vida social ocidental moderna. Ver sobre o tema Duarte (1998). No caso da Antropologia das Emoções, os trabalhos de Lutz apontam para as mesmas questões, referindose a uma preocupação sobre controle/descontrole de emoções no âmbito da "etnopsicologia" ocidental (LUTZ, 1988). Ver também Coelho e Rezende (2010).

${ }^{6}$ Segundo Gould: "The emotional content of the political discourse, in fact, suggests an indissociable relationship between lesbian and gay politics, on the one hand, and lesbian and gay ambivalence about self and society, on the other" (2001, p.142).
} 
consideradas confusas e eram relegadas a atividades práticas, sem envolver maior responsabilidade com o ideário da ONG, embora pudessem atuar nos seus eventos e manifestações. Estava em questão uma economia moral, que se expressava ao hierarquizar as pessoas através das ações que poderiam desempenhar, se elas tinham responsabilidade ou não, se elas tinham controle pessoal ou não. Contudo, o que vale ressaltar agora é esse investimento progressivo que a pessoa HIV positiva faz em sua formação pessoal (buscando ajuda e informação), em uma ONG Aids, cuja dimensão multifacetada envolve a reavaliação das emoções que antes constituíam uma experiência de vida pessoal em crise, e um projeto de conscientização pessoal que implica, aos poucos, sua automodelação como ativista. Em seu caráter denso, as emoções também precisam ser tratadas na ação política. Deve-se entender que a linguagem das emoções pode ser constituída através da dimensão política, associada a fenômenos e contextos sociais. Aqui, a "luta" ativista contra a Aids era uma recusa ao estigma que envolvia a pessoa com HIV, tal como acontece com os movimentos sociais que fortalecem identidades coletivas (GOODWIN; JASPER; POLLETTA, 2001), além da busca por direitos específicos e a garantia de sua "dignidade", o que expõe o sentido moral que orienta o ativismo HIV/Aids. Há, então, uma articulação estreita da construção das emoções tanto em seu processo de reelaboração pessoal, após um contexto de crise provocado pela doença e pela deflagração de sua experiência, como na mobilização que elas passam a ter quando a pessoa se forma como ativista. Isso irá se expressar tanto na dinâmica societária interna da ONG como também em sua visibilidade pública, sobretudo em eventos coletivos de caráter político. Seguindo Gould, pode-se pensar que a automodelação como ativista de ONG Aids mobilizava uma nova configuração de emoções (2001), que se mostrava através de um investimento específico no autocontrole pessoal que neutralizasse minimamente o impacto causado pelo estigma e experiência da doença, sobretudo o medo, a vergonha, a culpa e a tristeza causados pela infecção do HIV. Essa nova configuração emocional tinha sua expressão discursiva pública. Dessa forma, as vidas e trajetórias pessoais encontravam um projeto político coletivo, cujas ações e discursos remetiam a uma configuração de emoções com uma dimensão pública relevante. 


\section{Ativismo social de HIV/Aids: emoções, solidariedade e política}

A sensibilização emocional faz parte inerente da vida política e da maioria dos discursos de protesto, dispondo-se a constituir vínculos de solidariedade, lealdade e articulação entre os membros dos movimentos sociais, sem deixar de angariar apoio através de sentimentos de compaixão, raiva e solidariedade entre as pessoas que assistem à uma manifestação (GOODWIN et al., 2001, p.15). Trata-se de fator central para o ativismo social que estamos considerando, tal como constatou Gould (2009, p.439), apresentando-se através da correlação complexa entre os contextos abordados, sua historicidade e as emoções que se tornam mais visíveis e operantes. Desde a década de 1980, muitas ONGs AIDS buscaram sensibilizar e tornar mais públicas as demandas sobre doença, preconceito, descaso governamental, direitos das pessoas soropositivas e a circulação de ideias sobre solidariedade, cidadania e ativismo. Isso foi levado adiante por boa parte das ONGs, inclusive o GPV. Deve-se destacar que uma das estratégias das ONGs Aids foi a organização de eventos públicos que visassem à mobilização coletiva. Se esses eventos tiveram repercussão, dependeu dos contextos e das articulações com outros agentes, inclusive a imprensa, que foi, desde a eclosão da epidemia, um elemento institucional crucial para as definições culturais da Aids. Buscava-se posicionar-se social, política e culturalmente diante de discursos e imagens negativas da epidemia e das pessoas doentes, sobretudo aqueles que eram veiculados pela imprensa brasileira.

Em contraposição e reação a esse senso comum da Aids, a realização de eventos públicos por parte das ONGs era uma estratégia importante para a circulação social de concepções ideológicas, críticas sobre as políticas públicas e governamentais de saúde, além de estimular a formação dos seus membros, dotando-os pouco a pouco com o sentido de 'voluntários' e 'ativistas', termos interessantes para pensar as conexões com ideias e práticas de mobilização social e política da AIDS em termos globais (EPSTEIN, 1996; BASTOS, 1999; VALLE, 2000; GOULD, 2009).

Deve-se acrescentar que uma das questões que atormentava as lideranças das ONGs Aids, inclusive o GPV, foi a incorporação de pessoal, especialmente os voluntários, mas que ele fosse se capacitando e tornandose um multiplicador de suas concepções e práticas. Tais agruras seriam compensadas pela formação de pessoal que teria atributos próprios de conscientização e expertise, próprios para difusão e mediação do saber 
local, pautados em um ideário de conhecimento autorizado de prevenção do HIV/Aids, o que se aproxima de um modo de mobilização e controle de 'competência social e técnica' (BOURDIEU, 1989), a qual envolve a mobilização de capital cultural e social, o que consiste no dilema da lealdade e do recrutamento pessoal em grande parte dos movimentos sociais (GOODWIN; JASPER, 2006). Essa formação continuada de voluntários e pessoal 'qualificado', voltado e alinhado para práticas políticas e posicionamentos públicos, expressava-se na realização de eventos coletivos, que se tornaram socialmente significativos e historicamente marcados. No caso da epidemia, o evento que magnetiza isso de modo mais expressivo é o dia $1^{\circ}$ de dezembro, consagrado em termos globais como o Dia Mundial de Luta contra a Aids.

Desse modo, a criação das ONGs Aids, cuja proposta era a de disseminação de conhecimento técnico autorizado de prevenção a doenças, conciliava-se com a apresentação das entidades e de suas equipes, majoritariamente de pessoal voluntário, em situações, contextos e eventos públicos. No final da década de 1980 e durante grande parte da década passada, uma importante estratégia de difusão de ideias e práticas ativistas envolvia a organização de eventos coletivos de caráter político-ideológico, muitas vezes agenciando modelos (ritualizados) de ação direta, tal como faziam os coletivos

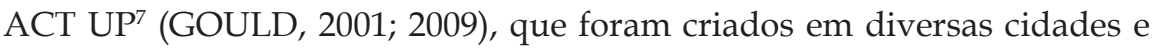
países e tiveram repercussão também no Brasil. Citado em material escrito de ONGs, o ACT UP marcava-se pelas práticas de protesto e reivindicação política em contextos públicos estrategicamente definidos, buscando atingir, social e emocionalmente, determinadas entidades e instituições. Em uma entrevista, uma antiga liderança do GPV refere-se aos primeiros anos da ONG, quando a presença de Herbert Daniel, seu idealizador e um dos seus fundadores, foi marcante:

“Eram reuniões onde a gente discutia solto, mas sempre tentando
caminhar para a política. Porque era a coisa do [Herbert] Daniel.
Tinha o ACT UP. Estava em plena movimentação naquela época.
Então, a gente tinha uma certa ideia de capturar esse espírito do
ACT UP, de denúncias, das coisas de violação do direito civil,
discutir a discriminação, discutir a questão do sangue. Era a

${ }^{7}$ ACT UP, AIDS Coalition to Unleash Power. 
questão da sexualidade. Então, era preconceito mesmo. As drogas. Aparecia muita gente. A discussão era essa. Muito política! Mas era o que eu te digo: era o Daniel falando. (...) O Pela Vidda tem uma influência dessa ideologia do ACT UP, que é a forma de ver a soropositividade como uma questão política e que era intervindo politicamente que a gente trabalharia as coisas. A questão da soropositividade era uma questão de direitos. Sendo de direitos é uma questão da humanidade, uma questão de todos, porque os direitos humanos são de todos".

[Homem; 36 anos; HIV+, Rio de Janeiro].

Junto de outras ONGs, o GPV notabilizou-se na organização de eventos com pessoal voluntário, mesmo em pequeno número, em locais públicos do Rio de Janeiro que tivessem impacto nos meios de comunicação de massa, buscando atingir as posições institucionais das autoridades e políticas governamentais ou, então, questionando criticamente empresas farmacêuticas. Como a literatura especializada reconhece, as emoções estão presentes em todo o processo histórico que constitui e refaz os movimentos sociais e políticos, que envolvem tanto práticas discursivas quanto expressões e mensagens de medo, temor, ansiedade, raiva, agressividade, etc. Muitas vezes, a questão moral trata-se de um aspecto central desses movimentos atravessados por fortes dimensões emocionais (GOODWIN et al., 2001).

Na década de 1990, houve um evento no Cristo Redentor, outro no Aterro do Flamengo, quando um grande plástico imitando um preservativo foi inserido em um obelisco do parque; uma manifestação na Praça Nossa Senhora da Paz, quando ela foi cercada por voluntários e ativistas formando uma roda de mãos dadas; o Largo do Machado e o Largo da Carioca também tiveram eventos. De modo frequente, o espaço público da Cinelândia é palco de atividades, especialmente voltadas para o Dia Mundial de Luta contra a Aids. Para se posicionar contra a Igreja Católica, o GPV se reuniu ao grupo Atobá de militância homossexual, à ABIA e a outras ONGs e 'crucificou' uma jovem HIV positiva na Cinelândia no ano de 1994. Na Conferência Mundial de Meio Ambiente, a Eco-92, o GPV e outras ONGs montaram barracas no Aterro do Flamengo onde eram divulgadas as ideias ativistas de solidariedade e do viver positivamente com Aids. Eventos em shoppings, como o Rio Sul, foram organizados com a presença de artistas da TV e músicos, sem contar a participação desde 1995 nas paradas anuais LGBT da diversidade sexual. Entendemos que todos esses eventos buscavam 
atrair e recrutar novos membros através de "expectativas emocionais" produzidas culturalmente (GOODWIN; JASPER, 2006). Com certeza, a ideia de solidariedade tinha forte sentido emocional, que evocava ao mesmo tempo compaixão, companheirismo e confiança, mobilizando e engajando pessoas, social e politicamente, na luta contra a Aids. Segundo Goodwin e Jasper (2006), pode-se dizer que "solidariedades afetivas" estavam sendo produzidas ao mesmo tempo que relações e vínculos societários eram criados e fortalecidos, gerando um ativismo social pautado em uma disputa moral sobre morte e vida, medo e vergonha, solidão e amizade.

Nos eventos coletivos e manifestações públicas, distribuíam-se grandes quantidades de preservativos. Algumas formas simbólicas foram eleitas e passaram a servir como elementos centrais de exibição, conferindo tangibilidade aos conteúdos propostos nas manifestações, tal como o laço vermelho, que é um ícone global da luta contra a AIDS, disposto muitas vezes ao lado de embalagens de preservativos. Eram apresentadas, expostas ou exibidas as ideias-valor do GPV e de muitas ONGs AIDS através de cartazes, faixas e performances teatrais com finalidade 'educativa' de 'conscientização' e com o pretexto de estimular, assim, o fim do preconceito com o uso ritual de frases de efeito político e simbólico: "Dinheiro faltando. AIDS sobrando", "Chega de Burocacria", "Contra a vampiragem, a solidariedade"; "Responsabilidade e direitos: compartilhemos", "Tenho AIDS, tenho pressa", "Toda pessoa com AIDS tem uma família"; "Somos todos iguais"; "O pré-conceito afasta"; "Aceite a diversidade"; "Evite a AIDS, Viva a Vida"; "Todo mundo convive com a AIDS". Ao mesmo tempo, posicionava-se publicamente contra o descaso das agências governamentais, por exemplo na distribuição irregular de remédios antirretrovirais. Em alguns eventos, foram usadas grandes caixas de papelão imitando caixas e frascos de remédios (AZT, DDI, Viread, Atazanavir, Kaletra, Efavirenz, etc). Nessas situações, colocava-se em questão a mudança de uma posição passiva das pessoas soropositivas, deslocando o sentido de doente/paciente para o de ativista HIV positivo, comprometido socialmente, cuja agência repercutia na ideia de lutar por direitos e ter conhecimento autorizado, dotado na própria experiência da doença, sobre o próprio tratamento e o consumo de medicamentos (EPSTEIN, 1996; NGUYEN, 2010).

Os corpos dos ativistas e voluntários serviam constantemente de suporte e instrumento técnico das questões a serem destacadas nas manifestações e eventos públicos: rostos pintados, máscaras de palhaço, véus negros ou cor de pele, aparentando preservativos, cobrindo as pessoas, atores de sunga e 
biquínis encenando uma performance 'extrema', digamos, nas escadarias da Câmara Municipal, litros de tinta vermelha jogados no chão. Segundo Flam (2005), certos movimentos sociais esperam chocar o público de modo performativo, a fim de tirá-lo de sua rotina cotidiana, buscando, assim, transformar o enquadramento emocional do mundo vivido. Nos eventos públicos do ativismo de HIV/Aids, havia a intenção de desestabilizar e criticar o preconceito e as práticas de estigmatização, além de estimular, através da presença corporal e da própria performance, uma mudança de atitude e favorecer o posicionamento crítico diante da epidemia. Com certeza, esses fatos relacionam-se com uma preocupação autorreflexiva e inquieta sobre o corpo, em sua materialidade, na medida em que ele colocava a própria discussão sobre o cuidado de si e a finitude, considerando a visão carregada de conotações morais e fatalidade que esteve associada à Aids por muito tempo, especialmente nas décadas de 1980 e 1990. Concordo com Pierre Bourdieu, quando afirma: "Aprendemos pelo corpo. A ordem social se inscreve nos corpos por meio dessa confrontação permanente, mais ou menos dramática, mas que sempre confere um lugar importante à afetividade e, mais ainda, às transações afetivas com o ambiente social" (1999, p.172). Gostaria ainda de salientar que se reaprende através do corpo, pois me parece uma questão crucial para se entender as reelaborações societárias pelas quais passam as pessoas com HIV, com reajuste emocional evidente, sobretudo aquelas que se inseriram no ativismo social. Assim, corpo e emoções estão intimamente imbricados na intencionalidade e nas orientações pragmáticas que constituem as práticas e significados do ativismo HIV/Aids. Como Goodwin et al. (2001) sugerem: "As emoções podem ser estrategicamente usadas pelos ativistas e ainda serem a base para pensamento estratégico" (p. 9 - tradução minha).

A relação entre os movimentos sociais e o uso da música vem sendo sugerida por autores como Eyerman e Jamison (1998), que registram como ela produz uma forte base emocional para a difusão de ideias ativistas. Além dos movimentos sociais não serem apenas políticos, eles viabilizam formas de recriação cultural, ressignificando as tradições musicais, inclusive as canções populares. No caso do ativismo de HIV/Aids, o uso de musicalidade, sons e canções conhecidas popularmente acrescia como um elemento cultural que potencializava a divulgação e a aceitação do movimento e das práticas das ONGs Aids, mas também ressignificava a produção cultural tanto da MPB como do pop-rock brasileiro da década de 1980. Isso passou a ser estimulado pouco a pouco, cada vez mais 
intensamente, quando os membros do GPV usavam canções conhecidas de artistas como Cazuza/Barão Vermelho, Renato Russo/Legião Urbana, Cássia Eller, Rita Lee, mesmo grupos internacionais, tais como a banda de pop-rock inglês Queen, capitaneada por Fred Mercury. Muitos desses artistas faleceram em consequência da Aids e serviam com certa ambivalência de inspiração política e social, sobretudo Cazuza. Como artistas, suas vidas confirmavam a concepção cultural corrente no Brasil de que eles possuíam uma "força positiva, criadora, natural e autêntica" (COELHO; REZENDE, 2010, p.25). Eram vistos como pessoas sensíveis, vulneráveis e instáveis, o que explicaria também sua própria doença e morte. De algum modo, suas carreiras e obras seriam exemplos de vidas criativas e "mais humanas", ceifadas pela Aids, tal como uma música cantada por Cazuza e sempre lembrada e tocada em eventos ativistas: "vida louca vida, vida breve, já que eu não posso te levar, quero que você me leve" ${ }^{\prime \prime}$. Essa fragilidade e força emocional não deve ser minimizada, exprimindo muito bem os significados das emoções para o mundo social que pesquisei. Ainda assim, o uso de suas imagens e músicas permite uma maior conotação simbólica, a fim de estimular mensagens e ideias positivas sobre o viver com Aids. Em 2000, usou-se, por exemplo, a frase de efeito "Quero mais saúde, me cansei de lero-lero, dá licença, mas eu vou sair do sério", tomando emprestado refrão de uma canção de Rita Lee ${ }^{9}$, cujo sentido ambíguo podia conotar raiva e indignação contra os impasses da política pública de saúde. Havia implicações, na verdade, bem maiores, pois os eventos e sua musicalidade podiam motivar filiações e a participação de pessoas, soropositivas ou não, no GPV e outras ONGs, tal como o relato de uma antiga voluntária sobre o primeiro Encontro ativista de que participou, o Vivendo de 1997, que tinha reunido mais de mil pessoas:

“Logo de primeira, quando eu entrei no auditório tinha alguém falando que tinha 15 anos de soropositividade! Eu queria levantar e bater palmas pro cara. Para mim, assim: “Que maravilha isso! É isso que eu queria ouvir". Muito bom! Tive alguns bons contatos

\footnotetext{
${ }^{8}$ Trata-se da canção "Vida Louca Vida", de autoria de Lobão e Bernardo Vilhena, gravada pelo cantor Cazuza (1958-1990) no disco “O Tempo não Para” de 1988 (gravadora Polygram/ Universal Music).

${ }^{9}$ Frase da canção "Saúde", de autoria de Rita Lee e Roberto de Carvalho, gravada pela cantora no disco "Saúde" de 1981 (gravadora SOM LIVRE).
} 
lá dentro. No domingo, fiquei maravilhada. ... O fechamento geral, que tocou aquela musiquinha [We are the Champions] do Fred Mercury [grupo Queen]. Aí, todo mundo chora! É lindo. Eu fico arrepiada quando lembro daquele momento para mim, especificamente, que estava passando por aquele processo. Que tudo mundo tinha passado e tal. Tinha uma galera ali que era soropositiva. A questão da luta contra a Aids, entendeu? Isso para mim foi assim muito vivo, muito franco. Eu me apaixonei pelo grupo! Tanto é que domingo acabou o Encontro e na segunda-feira eu estava lá no grupo, mas não tinha atividade. Fui na segunda-feira para participar da recepção. Fizeram um recesso rápido, porque foi muita pauleira de trabalho. Eu cheguei lá com uma amiga: "Eu vou lá conhecer. Quero me filiar! Tem que preencher ficha?" Eu queria preencher ficha! Eu me lembro que eu queria assim: "Eu quero me cadastrar". Eu quero me casar com o grupo [ri]". [Mulher, 30 anos, HIV+, Rio de Janeiro].

O sentido emocional envolvendo o contato e a entrada no GPV articulavase com a construção de uma identidade soropositiva e de uma experiência singular, corporificada, que se acionava, na ocasião da entrevista, com a memória emocional do evento, ao 'arrepiar-se' quando lembrava daquele momento, mas expunha ainda mais o sentido autêntico que marcava essa vinculação imediata, "viva" e "franca", com a ONG e com o ativismo social da Aids, vista metaforicamente como uma "paixão" que deveria se tornar rapidamente um casamento. A associação direta entre afeto, em sua dimensão subjetiva, com a prática social, que envolve um projeto sociopolítico, é exemplar. Para a interlocutora, a memória da participação no evento político - "onde todo mundo chora" - ajudava a recuperar uma experiência emocional que explica sua vinculação ao ativismo social da Aids. Deve-se reconhecer que as pessoas em eventos coletivos se manifestavam de modo explícito diante de sua performatividade emocional e discursiva. Como afirmam Abu-Lughod e Lutz, precisamos entender os discursos emocionais como atos pragmáticos e performances comunicativas (1990, p.11), que podem se manifestar através de tipos discursivos específicos. Em nosso estudo, as canções populares brasileiras ou estrangeiras têm essa clara eficácia cultural e emocional, articulando trajetórias de vida a eventos sociais e ativismos políticos.

Mas as emoções também comunicam sobre questões, conflitos e disputas sociais. Havia, por um lado, as manifestações públicas a fim de criar sensibilização social sobre a epidemia, a divulgação de práticas de 
prevenção, a afirmação de ideias e práticas de 'solidariedade' contra o preconceito, a reivindicação política de direitos à saúde e à cidadania plena. Elas passaram a ser planejadas e organizadas a cada ano, sobretudo para eclosão no dia $1^{\circ}$ de dezembro. Por outro lado, as ONGs Aids buscaram também se posicionar através de manifestações e atos públicos contra certos alvos críticos, especialmente o Ministério da Saúde e as agências governamentais, além de fazer um posicionamento diante das empresas de planos de saúde, das embaixadas de países, como os Estados Unidos, que passaram a exigir visto de entrada para pessoas com HIV, empresas farmacêuticas, a Igreja Católica, a Varig, etc. Deve-se acrescentar que tais manifestações e atos coletivos podiam estar associados a eventos de caráter programático do "movimento social de Aids", que passou a se reunir de modo sistemático desde a década de 1980. Encontros, congressos e seminários passaram a ser organizados e grande parte deles envolvia 'ativistas', 'voluntários', lideranças, profissionais de saúde e de ONGs, além de agentes e pessoal governamental. Um dos principais eventos tem sido o Encontro Nacional de Pessoas vivendo com HIV e AIDS, conhecidos como Vivendo, organizado regularmente pelo GPV e seus parceiros institucionais no Rio de Janeiro desde 1991. Embora tivesse um público reduzido em seu início, o Vivendo passou a atingir cifras de participação antes insuspeitas, chegando até a mais de duas mil pessoas. Na metade da década de 1990, estes encontros alcançaram seu período áureo em razão dos recursos acessíveis da época, mostrando a acelerada profissionalização das equipes das ONGs Aids, além do contexto peculiar e complexo das 'parcerias' entre o 'movimento social', ou seja, as ONGs, e as agências governamentais. Todos estes eventos foram situações marcantes para entender como solidariedades e conflitos sociais podem ser expostos através de linguagens emocionais ${ }^{10}$.

Deve-se ainda salientar que o tempo sempre esteve presente, além de fator social, enquanto uma questão simbolicamente relevante, na maioria das manifestações que envolvem a 'luta contra a AIDS". Traziam à tona a relaboração de projetos de vida a partir de uma nova perspectiva sobre o

\footnotetext{
${ }^{10}$ A década de 1990 marcou-se por uma provisão de recursos dirigidos ao Brasil. Projetos de intervenção de ONGs Aids foram aprovados, assinalando as 'parcerias' entre o governo e o movimento social (GALVÃO, 2000). Nesse período, o impacto dos projetos do Banco Mundial e do apoio de agências de cooperação internacional foi enorme (VALLE, 2013).
} 
presente e o futuro, que deveriam ser sempre reatualizados. A cada evento que seria organizado pela ONG e muitas outras, a questão do tempo que, aos poucos, passava seria tornada elemento importante da própria ação social, que se dimensionava através de uma ideia de agência "cidadã" dos 'ativistas' diante das práticas e posições da administração pública, mas se articulando igualmente através dos depoimentos individuais quanto à redefinição de seus projetos de vida e aos novos propósitos que se adequavam a trajetórias pessoais que estavam sendo reformuladas em termos cotidianos e da intimidade. Nesse caso, muitos relatos sobre a entrada no GPV destacavam a significativa mudança de perspectiva que era causada, quando imagens, ideias e práticas negativas que privilegiavam morte, doença eisolamento, potencializadas a partir do autorreconhecimento de um status sorológico positivo para o HIV, seriam, ao menos em parte, questionadas e desnaturalizadas por uma nova perspectiva a favor da vida. Era, assim, que se enunciava o compromisso e a responsabilidade com as propostas da ONG e ainda uma 'conscientização' sobre a AIDS, que exigia, de algum modo, participação como voluntário nos eventos do GPV.

O tempo também se associava à relação entre três aspectos: memória, emoções e política. Estou tratando de um período que perdurou, sobretudo, do final da década de 1980 e se estendeu até o final do século XX. Na verdade, tratava-se de uma preocupação sobre a memória das pessoas falecidas em razão da Aids, que sugeria uma dimensão evidente de sofrimento que precisava ser tornado público, tal como sugere Mauss (1981), e, ainda mais, politizado. Através da organização de eventos que rememoravam as mortes causadas pela epidemia, tentava-se criar atenção do grande público, "sensibilizá-lo" e também valorizar a ideia de solidariedade, tratando-se, portanto, de uma obrigatoriedade moral (MAUSS, ibid), que se expressava em experiências e contextos carregados de valores societários e políticoemocionais. Essa estratégia tinha uma dimensão global e esteve presente em diversos ativismos locais da Aids. Foram muito frequentes as vigílias com velas, os chamados candlelights, que muitas vezes aconteciam também no Dia Mundial de Luta contra a Aids. Além das vigílias, Ongs como o GPV apropriaram-se de uma prática cultural também de extrema densidade emocional: a elaboração de colchas de retalhos, com os nomes de pessoas falecidas. Essas colchas eram guardadas e usadas em eventos coletivos. Evidentemente, a memória e a sua dimensão político-emocional estavam presentes na emergência do ativismo social de Aids. Estou considerando, portanto, os eventos e manifestações públicas das ONGs 
Aids em sua propositura e dimensão emocional, qual seja, em que medida a organização e manutenção de atividades sociais e políticas envolviam emoções específicas, especialmente indignação e raiva, e como elas puderam igualmente potencializar formas de apreensão e entendimento específico sobre a vida social.

\section{Conclusão}

Pretendi mostrar que a melhor forma de se estudar a relação entre emoções e política requer uma abordagem histórica e sociocultural. As emoções não podem ser encaradas de modo natural e estático, mas são significadas culturalmente a partir dos contextos em que estão sendo mobilizadas e expressadas através de relações sociais. Desse modo, considero que um evento crítico, como a descoberta do status sorológico HIV positivo, motiva, mobiliza e engaja uma pessoa para um processo complexo de decisões e ações que dependem de um trabalho emocional aberto a uma contínua transformação. As questões de autocontrole pessoal e automodelação como ativista, em um processo de redefinição biográfica, reajustam emoções de medo e vergonha em razão da doença. Elas passam a ser contrabalançadas, ainda que não completamente, com a aquisição de maior informação e responsabilidade na vida pessoal, o que inclui, por exemplo, a incorporação de práticas de sexo seguro. Defendida por ONGs como o GPV, a ideia de viver a vida positivamente sugere uma forma específica de lidar com as emoções, o que será também importante para o engajamento em novas práticas sociais e políticas.

$\mathrm{O}$ ativismo social contra a epidemia do HIV/Aids mostra como as emoções vêm sendo mobilizadas através das dinâmicas societárias, da incorporação de voluntários e ativistas, além da realização de ações e manifestações públicas de caráter político. Não é possível separar um plano de reflexão e conscientização racional e/ou ideológica e outro nível de experiência pessoal e coletiva em que as emoções seriam exibidas mais claramente. Ao contrário, a proposta do presente artigo foi a de mostrar como é indissociável lidar com consciência e emoções, que se evidenciam através das práticas e ações pessoais, cuja intencionalidade está explicitada, mas igualmente atravessada, por uma dimensão afetiva. Do mesmo modo, as práticas e ações coletivas de caráter político e público dependem de um trabalho emocional e de um engajamento interpretativo em que as 
emoções têm significação central. Nos dois planos ou níveis, apresenta-se uma linguagem emocional cujos significados e sentidos seriam captados e compreendidos por pessoas e grupos de acordo com contextos e relações cuja historicidade precisa ser encarada de modo privilegiado.

Nos tópicos anteriores, mostrei como diversas emoções puderam ser mobilizadas através da ação simbólica, sendo igualmente contextualizadas historicamente de acordo com os projetos, expectativas, ideias, que sustentam as práticas dos voluntários e ativistas de ONGs Aids, como o GPV. Assim, não creio ser necessário identificar determinadas emoções, associando-as de modo exclusivo a uma certa época, afinal o sentido intersubjetivo da linguagem cultural das emoções exploraria diversas expressões, ou seja, como apresentações do chamado trabalho emocional, sobretudo ao considerarmos as diversas pessoas e grupos envolvidos. As emoções referem-se às relações, não se reduzindo, portanto, a sentimentos isolados, concebidos apenas em sua interioridade psíquica. Nesse sentido, os eventos e situações que observei delinearam um jogo específico das emoções em razão das próprias interações entre as pessoas presentes. Contudo, algumas emoções foram reelaboradas e reconstituídas, ainda que a ideologia e a retórica possam permanecer com poucas alterações (GOODWIN et al., 2001, p.18), tais como a da solidariedade contra o estigma da Aids, que constitui de modo instrumental o foco-luta do ativismo social.

Portanto, o ativismo social vem sendo constituído por uma produção de mensagens e discursos ideológicos, além de eventos e manifestações públicas, cujo entendimento depende também de aspectos emocionais, não verbais, não estritamente calculados em termos instrumentais, mas dependem de uma experiência que é, ao mesmo tempo, ideológica e profundamente emocional, que produz, em sua própria existência, redes de relações, vínculos societários e uma dimensão de solidariedade e lealdade afetiva que precisam ser considerados em qualquer análise social. As emoções condicionam as possibilidades para o ativismo político, mobilizando ou engajando ou minimizando participação de pessoas de acordo com os contextos em que estão envolvidas. A automodelação como pessoa HIV+ e ativista de ONG Aids pode se apresentar através dessa dupla face da construção de si. 


\section{Referências}

ABU-LUGHOD, Lila; LUTZ, Catherine.

(1990). Introduction. In: Language and the politics of emotion. Cambridge, Cambridge University Press.

ARISS, Robert.

(1997). Against death: the practice of living with AIDS. Amsterdam, Gordon and Breach Publishers.

BASTOS, Cristiana.

(1999). Global Responses to AIDS: Science in Emergency. Bloomington, Indiana University Press.

BIEHL, João.

(2007). Will to live: AIDS therapies and the politics of survival. Princeton, Princeton University Press.

BIEHL, João; COUTINHO, Denise; OUTEIRO, Ana. (2001). Technology and affect: HIV/AIDS Testing in Brazil. Culture, Medicine and Psychiatry, 25.

BOURDIEU, Pierre.

(1999). Meditações Pascalianas. Rio de Janeiro, Bertrand Brasil.

(1989). A representação política: elementos para uma teoria do campo politico. In: Pierre Bourdieu; 0 poder simbólico. Rio de Janeiro, Editora Bertrand Brasil.

COELHO, Maria Claudia Pereira.

(2010). Narrativas da violência: a dimensão micropolítica das emoções. Mana, 16(2), p.265-285.

COELH0, Maria Claudia Pereira; REZENDE, Claudia Barcellos.

(2010). Antropologia das emoções. Rio de Janeiro, Editora FGV.

COHEN, Stanley.

(1972). Folk devils and moral panic. Londres, MacGibbon and Kee.
DAS, Veena.

(1996). Critical events: an anthropological perspective on contemporary India. 0xford, 0xford University Press.

DUARTE, Luiz Fernando Dias.

(1998). Investigação antropológica sobre doença, sofrimento e perturbação: uma introdução. In: Luiz Fernando Dias Duarte; Ondina Fachel Leal (orgs.); Doença, sofrimento, perturbação: perspectivas etnográficas. Rio de Janeiro, Editora Fiocruz.

ELIAS, Norbert.

(1994). O Processo Civilizador. Rio de Janeiro, Jorge Zahar Editor.

EPSTEIN, Steven.

(1996). Impure Science: AIDS, Activism, and the Politics of Knowledge. Berkeley, University of California Press.

EYERMAN, Ron; JAMISON, Andrew.

(1998). Music and social movements: mobilizing traditions in the 20th Century. Cambridge, Cambridge University Press.

FLAM, Helena.

(2005). Introduction. In: Helena Flam; Debra King (Eds.); Emotions and Social Movements. Londres, Routledge.

GALVÃ0, Jane.

(2000). AIDS no Brasil: a agenda de construção de uma epidemia. São Paulo, ABIA / Editora 34.

GOODWIN, Jeff; JASPER, James; POLLETTA, Francesca.

(2001). Introduction. Why emotions matter. In: JeffGoodwin; James Jasper; Francesca Polleta (Eds.); Passionate Politics: emotions and social movements. Chicago, The University of Chicago Press.

GOODWIN, Jeff; JASPER, James.

(2006). Emotions and social movements. In: Jan Stets; Jonathan Turner (Eds.); Handbook of the Sociology of Emotions. Nova Iorque, Springer. 
GOULD, Deborah.

(2001). Rock the boat, don't rock the boat, baby: ambivalence and the emergence of militant AIDS activism. In: Jeff Goodwin; James Jasper; Francesca Polletta (Eds.); Passionate Politics: emotions and social movements. Chicago, The University of Chicago Press.

GOULD, Deborah.

(2009). Moving Politics: Emotion and Act Up's Fight against AIDS. Chicago, The University of Chicago Press.

GUIMARÃES, Carmen Dora.

(2001). AIDS no feminino: por que a cada dia mais mulheres contraem AIDS no Brasil?. Rio de Janeiro, Editora da UFRJ.

KNAUTH, Daniela Riva.

(1998). Morte masculina: homens portadores do vírus da Aids sob a perspectiva feminina. In: Luiz Fernando Dias Duarte; Ondina Fachel Leal (Orgs.); Doença, sofrimento, perturbação: perspectivas etnográficas. Rio de Janeiro, Editora Fiocruz.

LUTZ, Catherine.

(1988). Unnatural emotions: everyday sentiments on a Micronesian Atoll \& their challenge to Western Theory. Chicago, Chicago University Press.

MAUSS, Marcel.

(1981). A expressão obrigatória dos sentimentos (rituais orais funerários australianos). In: Ensaios de Sociologia. São Paulo, Perspectiva.

\section{MINISTÉRIO DA SAÚDE.}

(2013). Boletim Epidemiológico - Aids e DST. Ano 2, n. 1. Brasília, Secretaria de Vigilância em Saúde - Departamento de DST, Aids e Hepatites Virais.

NGUYEN, Vinh-Kim.

(2010). The Republic of Therapy: triage and sovereignty in West Africa's Time of Aids. Durham, Duke University Press.

PARKER, Richard.

(1990). Responding to AIDS in Brazil. In: Barbara Misztal; David Moss (Eds.); Action on AIDS: National Policies in Comparative Perspective. Westport, Greenwood Press.

PARKER, Richard.

(1994). A Construção da solidariedade: AIDS, sexualidade e política no Brasil. Rio de Janeiro, ABIA / IMS-UERJ / Relume Dumará.

SEFFNER, Fernando.

(1995). Aids, estigma e corpo. In: Ondina Fachel Leal (Org.); Corpo e Significado. Porto Alegre, Editora da Universidade.

SILVA, Cristina Câmara da.

(1999). Ativismo, ajuda mútua e assistência: a atuação das Organizações nãogovernamentais na luta contra a Aids. Tese de Doutorado apresentada ao Programa de Pós-graduação em Sociologia e Antropologia (PPGSA) da Universidade Federal do Rio de Janeiro (UFRJ). Rio de Janeiro.

SONTAG, Susan.

(1983). Illness as metaphor. Londres, Penguin Books.

STRAUSS, Anselm.

(1999). Espelhos e máscaras. São Paulo, Edusp.

VALLE, Carlos Guilherme do.

(2008). Apropriações, conflitos e negociações de gênero, classe e sorologia: etnografando situações e performances no mundo social do HIV/Aids. Revista de Antropologia, 51(2). São Paulo.

(2002). Identidades, doença e organização social: um estudo das pessoas vivendo com HIV e AIDS. Horizontes Antropológicos, 17. Porto Alegre.

(2000). The Making of People Living with HIV and AIDS: identities, illness, and social organization in Rio de Janeiro, Brazil. Ph.D. Dissertation presented to University of London.

VALLE, Carlos Guilherme do.

(2010). Corpo, doença e biomedicina: uma análise antropológica das práticas corporais e de tratamento entre pessoas com HIV/Aids. Vivência, 35. Natal. 
VALLE, Carlos Guilherme do.

(2013). From dissidence to partnership and back to confrontation again? The current predicament of Brazilian HIV/AIDS activism. In: Raymond Arthur Smith (Ed.); Global HIV / AIDS activism, politics, and policy: persistent challenges and emerging issues. Califórnia, Praeger Publishers.
VEJA. Cazuza. Uma vítima da AIDS agoniza em praça pública (matéria em revista). N.1077, 26 de abril de 1989.

\section{Recebido em}

dezembro de 2016

Aprovado em

março de 2017 